\title{
Proposta de práticas administrativo-pedagógicas que possam contribuir para o desempenho dos alunos de escolas municipais do ensino fundamental na Prova Brasil
}

\author{
Alexandre Pereira Salgado Junior ${ }^{\text {a }}$ \\ Juliana Chiaretti Novi a
}

\section{Resumo}

O objetivo desta pesquisa foi aplicar a metodologia de Salgado Junior e Novi para identificar práticas administrativo-pedagógicas que possam contribuir para o desempenho dos alunos de escolas municipais do ensino fundamental na Prova Brasil. Diferentemente dos estudos já realizados relacionados à temática abordada neste artigo, a metodologia divide-se em duas etapas: qualitativa e quantitativa. Assim, na primeira etapa, de caráter quantitativo, foram comparadas sete escolas eficientes, calculadas na fronteira da Análise Envoltória de Dados (DEA) a três escolas ineficientes, escolhidas por julgamento e conveniência. $\mathrm{Na}$ segunda etapa, de caráter qualitativo, visando compreender os processos internos que levam escolas com características similares a obterem desempenhos diferentes, foram realizados estudos de múltiplos casos. Como resultado foi possível identificar evidências de que 26 práticas administrativo-pedagógicas podem contribuir para o desempenho dos alunos na Prova Brasil. Espera-se, poder auxiliar no processo de melhoria da qualidade educacional, políticas públicas e gestão dos recursos para a Educação no país.

Palavras-chave: Ensino fundamental. Prova Brasil. Análise Envoltória de Dados (DEA). Eficiência e investimento em educação.

\footnotetext{
a Universidade de São Paulo - USP, Faculdade de Economia, Administração e Contabilidade, Departamento de Administração. Ribeirão Preto, São Paulo, Brasil.
} 


\section{Introdução}

A educação implica no crescimento e desenvolvimento socioeconômico e político de um país, pois proporciona melhores condições aos indivíduos, que se tornam cidadãos ao construírem uma base de conhecimento e aprendizagem para utilizar ao longo de sua vida (FRANCO, 2008).

Para Andrade (2011, p. 324), arguições sobre desenvolvimento devem considerar que "a qualidade e não a quantidade da educação é a variável mais importante para explicar o crescimento econômico". Em 2012, cerca de 29,7 milhões de alunos estavam matriculados no ensino fundamental, sendo $68,2 \%$ desses alunos nas redes municipais brasileiras (BRASIL, 2013).

Segundo Soares e Candian (2007), o sistema brasileiro de educação apresenta um baixo nível de desempenho dos alunos, principalmente, se comparado ao de outros países, conforme o relatório da Economist Intelligence Unit (2012). Dessa forma, são necessários avanços para se garantir uma melhoria da qualidade da educação no país (GOMES, 2005; PINTO, 2013). E, dentre os mecanismos que podem contribuir para isso, destacam-se os testes padronizados em avaliações em larga escala. Entretanto, apesar da divergência entre alguns estudos sobre seu real impacto para mensurar a qualidade da educação (ALVES; SOARES, 2013; OLIVEIRA; ARAUJO, 2005), elas constituem uma forma de se avaliar o desempenho dos alunos no Brasil (BONAMINO; SOUSA, 2012; FERNANDES; GREMAUD, 2009; GATTI, 2009; MENDES JUNIOR, 2010). Ademais, as políticas educacionais, comumente, estão sendo orientadas pelos desempenhos dos alunos nessas avaliações (EYNG et al., 2013; SOUSA; OLIVEIRA, 2010), no entanto, elas esbarram na frequente limitação dos recursos destinados às escolas públicas brasileiras (DIAZ, 2012; ZOGHBI et al., 2009).

Dessa forma, tornam-se fundamentais pesquisas que identifiquem, dentre o universo de atividades praticadas no âmbito escolar, aquelas que possam contribuir para promover a melhoria do desempenho dos alunos nos testes padronizados, além de possibilitar um planejamento para que Secretarias Municipais de Educação (SMEs), diretores e escolas possam orientar a destinação dos seus recursos disponíveis.

Para Teixeira (2009, p. 232), "pesquisadores brasileiros intensificam a busca pelas práticas que constituem escolas de qualidade e que influenciam no ensino", no entanto, as pesquisas já realizadas se dividem, basicamente, em dois grupos: quantitativas e qualitativas. O primeiro grupo, utiliza como metodologia para identificação das práticas que influenciam no desempenho dos alunos, o modelo input-output. Geralmente, essas pesquisas procuram analisar se os inputs (recursos 
humanos, materiais e financeiros) são capazes de acrescentar algo aos outputs (desempenho escolar dos alunos). Nesta abordagem, as escolas permanecem como "caixas-pretas", na medida em que seus processos internos, ou seja, aqueles que podem levar aos resultados dos alunos, são desconsiderados (GAME, 2002).

Muitos dos trabalhos quantitativos geram resultados a partir de uma base de dados pública, tais como os micro dados disponibilizados pelo Ministério da Educação (MEC) (BIONDI; FELÍCIO, 2007; DWYER et al., 2007) e apresentam como vantagem a possibilidade de generalizações de resultados. No entanto, ainda não existe um consenso na literatura sobre muitos dos resultados gerados por esta abordagem (BUCHMANN, 2002; LEE; BRYK; SMITH, 1993; MAY, 2006).

O segundo grupo, de abordagem qualitativa, geralmente visa compreender os processos escolares internos, buscando indícios de como as escolas podem exercer um efeito positivo sobre o aprendizado dos alunos. Esta abordagem tem a vantagem de não considerar as escolas como "caixas-pretas".

Entretanto, existe a limitação de serem comparados grupos de escolas com bom desempenho, selecionadas por critérios que limitam a generalização dos resultados. Para GAME (2002, p. 13), "os estudos de caso nessa linha de pesquisa ainda estão bastante restritos aos países desenvolvidos. No Brasil, é recente o esforço de realizar pesquisas desse tipo".

Apesar dos estudos realizados pelo MEC/BID (BRASIL, 2010), Ernica e Batista (2011), Gouveia, Souza e Tavares (2009), Machado-Soares et al. (2011), Padilha et al. (2012), Soares et al. (2011), MEC/Unicef (BRASIL, 2006, 2008), Alves e Soares (2013), Franco et al. (2006), Postlethwaite e Ross (1992) e Sammons (2008), no intuito de identificar práticas, que podem influenciar no desempenho dos alunos, nem sempre a seleção das escolas é realizada com o objetivo de se comparar grupos similares, que tenham desempenhos diferentes explicados pelo efeito das escolas ou dos fatores associados a elas.

Portanto, realizar estudos com base nas escolas que apresentam os melhores resultados nos exames, como os já anteriormente realizados, não parece ser o melhor formato para esse tipo de pesquisa, pois se corre o risco de que sejam escolhidas as escolas que recebem os "melhores" alunos e não aquelas que mais podem contribuir para o desempenho deles (BROOKE; SOARES, 2008).

Nesse contexto, foi proposta por Salgado Junior e Novi (2014) uma metodologia quali-quantitativa que buscou utilizar as vantagens dos dois grupos de pesquisas, 
qualitativo e quantitativo, de forma integrada ou colaborativa. Nela, como critério para escolha e seleção das escolas é utilizada a Análise Envoltória de Dados (DEA), que classifica as escolas como eficientes e ineficientes, ou seja, em "alto" e "baixo" desempenho de seus alunos, dentro de variáveis input-output previamente estabelecidas. Posteriormente, são realizados estudos de múltiplos casos nessas escolas, visando entender seus processos internos e, dessa forma, identificar as práticas que melhor podem contribuir para o desempenho dos alunos nos testes padronizados.

Para GAME (2002, p. 13), "os estudos de caso nessa linha de pesquisa ainda estão bastante restritos aos países desenvolvidos. No Brasil, é recente o esforço de realizar pesquisas desse tipo". Em estudo realizado por Mesquita (2012, p. 587), ela conclui que "[...] aproximando os dados quantitativos com o ponto de vista dos atores da comunidade escolar, pode-se apreender as contribuições destes dois campos de investigação para refletir sobre a escola e a busca por mais qualidade".

Sendo assim, o objetivo deste estudo foi realizar uma aplicação da metodologia (SALGADO JUNIOR; NOVI, 2014), para identificar práticas administrativopedagógicas que possam contribuir para o desempenho dos alunos de escolas municipais do ensino fundamental na Prova Brasil. Para tanto, foram consideradas 10.157 escolas municipais do ensino fundamental distribuídas por todo o país, que realizaram a Prova Brasil em 2011 e tiveram um investimento por aluno, no mesmo ano, calculado com base nas Finanças do Brasil (FINBRA) e na base de dados do Ministério da Educação (MEC).

\section{Procedimentos Metodológicos}

A pesquisa utilizou o estudo de caso no intuito de se entender em profundidade os grupos (YIN, 2005) que, no caso da presente pesquisa, referem-se às escolas municipais do ensino fundamental eficientes e ineficientes em transformar investimento financeiro em nota na Prova Brasil. Posteriormente, os dois grupos serão comparados mensurando-se a frequência com que cada prática, que pode influenciar no desempenho dos alunos, for identificada.

A metodologia aplicada nesta pesquisa (SALGADO JUNIOR; NOVI, 2014), possui duas fases: quantitativa e qualitativa. Na primeira fase, de caráter quantitativo, para identificar as escolas municipais do ensino fundamental brasileiras eficientes em transformar investimento financeiro em nota na Prova Brasil, foi realizada uma análise não-paramétrica, por meio da aplicação da técnica de Análise Envoltória de Dados (DEA), na qual foi possível identificar, para o ano de 2011, sete escolas eficientes localizadas na fronteira de eficiência, em um universo das 10.157 escolas do Brasil. 
A escolha da técnica DEA ocorreu em função da correlação entre as duas variáveis $\left(\mathrm{R}^{2}=0,0315\right)$, restringirem a utilização de estatística paramétrica, onde as duas variáveis são: Investimento anual por aluno em 2011 e Nota padronizada da Prova Brasil em 2011. Ademais, a técnica DEA permite uma comparação de eficiência relativa entre os grupos estudados, fato este, importante para a pesquisa. Dessa forma, esta primeira fase, envolveu a seleção das escolas consideradas com melhor desempenho relativo e que servirão de benchmarking na comparação com um grupo de escolas ineficientes, na qual se objetiva identificar práticas administrativo-pedagógicas que levam escolas com investimentos, tamanho, localização e NSE similares a terem desempenhos diferentes na Prova Brasil.

Na segunda fase da pesquisa, de abordagem qualitativa, foi realizado um estudo de múltiplos casos nas sete escolas consideradas eficientes pela técnica DEA e em três escolas ineficientes (grupo de controle), escolhidas em função de características semelhantes às eficientes. Destaca-se essa importância de similaridade para se evitar que fatores como NSE, tamanho da escola, tamanho e localização do município possam viesar a pesquisa, uma vez que a literatura aborda a impossibilidade de se comparar escolas com diferenças nessas características.

Foram então identificadas e comparadas as frequências de cada prática administrativo-pedagógica em todas as dez escolas (eficientes e ineficientes) do estudo. A técnica de pesquisa utilizada para avaliar e analisar os resultados das entrevistas semiestruturadas realizadas junto às escolas eficientes e ineficientes, no estudo de múltiplos casos, na etapa qualitativa do trabalho, foi a análise de conteúdo. Ela constitui um instrumento que pode ser utilizado de múltiplas formas na pesquisa, tanto interdisciplinar como objetivamente, pois permite $o$ acesso a diversos contentos que, quando transformados em textos, são passíveis da aplicação dessa técnica (BARDIN, 2011).

A Figura 1 apresenta a descrição da aplicação da metodologia de Salgado Junior e Novi (2014).

\section{Aplicação da primeira fase da metodologia de Salgado Junior e Novi: fase quantitativa}

Foi utilizada a técnica DEA para o cálculo das escolas eficientes em transformar insumos em produtos. De acordo com Cooper, Seiford e Tone (2007), a DEA é uma técnica utilizada para avaliar o desempenho de um conjunto de unidades que são chamadas de Decision Making Units (DMUs) ou unidades tomadoras de decisão, que convertem múltiplos insumos (inputs) em múltiplos produtos (outputs). 


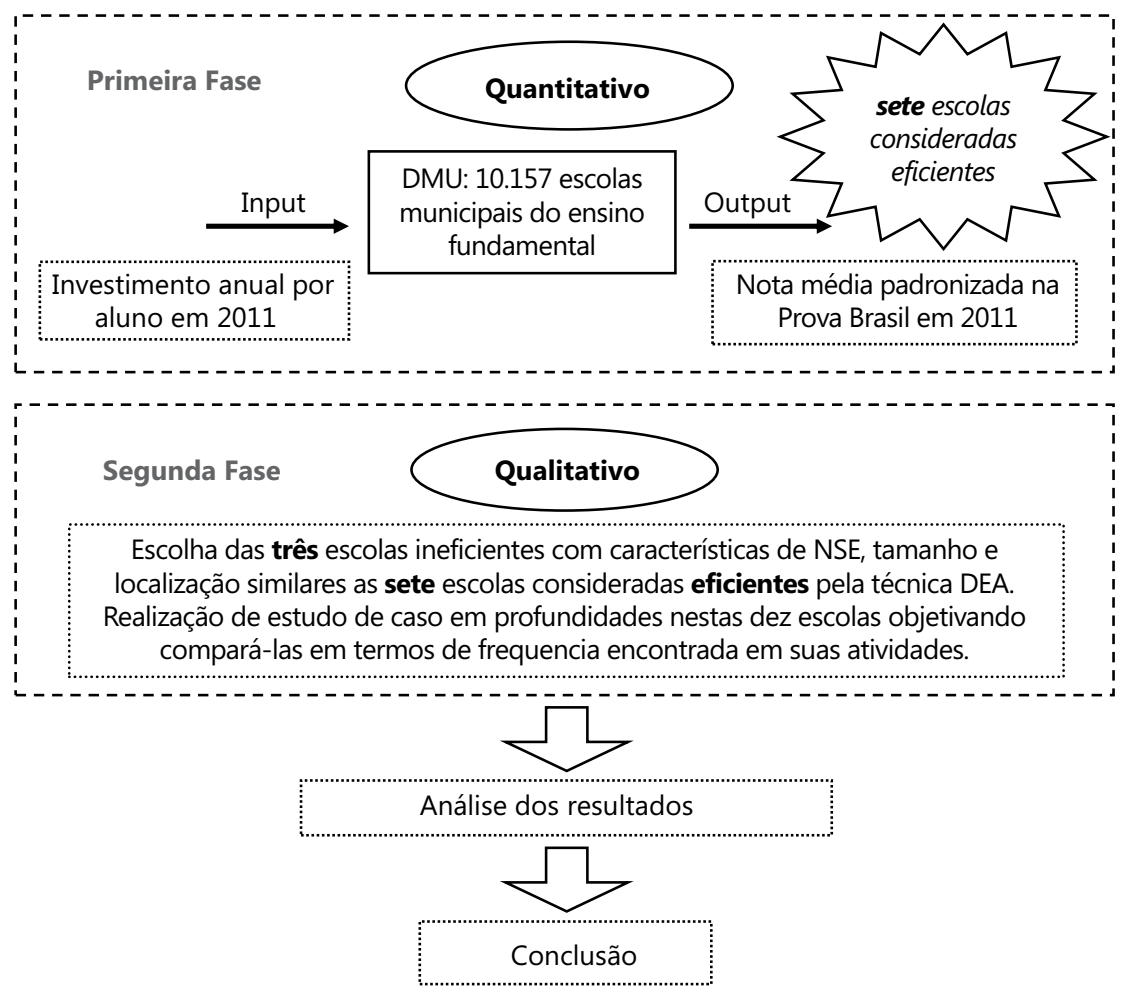

Fonte: Salgado Junior e Novi (2014).

Figura 1. Esquematização da metodologia proposta por Salgado Junior e Novi (2014).

Foram utilizados dados financeiros de investimento em educação disponibilizados pela Secretaria do Tesouro Nacional - FINBRA e pelo Instituto Nacional de Estudos e Pesquisas Educacionais Anísio Teixeira (Inep). Assim, utilizando os dados sobre o quanto o município investiu em educação fundamental anualmente, o número de alunos do fundamental em escolas municipais por município, além dos dados referentes às notas médias da Prova Brasil, em 2011, de escolas municipais do ensino fundamental II do Brasil foi possível calcular o investimento por aluno da rede municipal de cada município. Portanto, essas são as duas variáveis fundamentais para o cálculo das escolas eficientes pela técnica DEA.

Para a leitura dos dados do censo escolar foi utilizado o software Stata ${ }^{\circledR}$, do fornecedor StataCorp LP. Para a manipulação e configuração dos dados foi 
utilizado o software SAS ${ }^{\circledR}$, do fornecedor SAS Institute Inc., disponível nas instalações da FEA-RP/USP, uma vez que o software da Microsoft Excel ${ }^{\circledR}$ limita o número de linhas por planilha, restringindo sua utilização. Para o emprego do Stata ${ }^{\circledR}$, foi necessário realizar um conjunto de procedimentos: utilizou-se o Bloco de Notas $^{\circledR}$ do Windows para a leitura dos dados obtidos no site do Inep, em seguida, estes foram transferidos para o Microsoft Excel ${ }^{\circledR}$ para que fossem formatados.

A opção por escolas municipais, excluindo-se as estaduais, federais e particulares, deve-se à restrição do FINBRA em disponibilizar o investimento feito nas escolas municipais, uma vez que o município disponibiliza o quanto foi investido em ensino fundamental. Para obter o investimento por alunos, dividiu-se o investimento total do município em 2011 declarado pelo FINBRA, pelo número de alunos declarados pelos microdados do INEP.

Após a definição das variáveis a serem utilizadas no método DEA, é necessário definir sua orientação a ser empregada. Sobre a orientação da técnica DEA foi considerada mais adequada a utilização do modelo BCC, com orientação a output, por dois fatores principais: primeiro, pela impossibilidade de estabelecer uma relação de proporcionalidade entre inputs e outputs, quando é considerada a relação entre investimento em educação e nota na Prova Brasil, desta forma recomenda-se o modelo BCC; segundo, relacionado à orientação aos outputs, que consiste em calcular a escola com maior capacidade de gerar nota na Prova Brasil, considerando que todas as escolas tenham o mesmo investimento por aluno.

Essas informações foram utilizadas para aplicar a metodologia de Salgado Junior e Novi (2014) em 10.157 escolas municipais do ensino fundamental distribuídas por todo o país, que realizaram a Prova Brasil em 2011 e tiveram um investimento por aluno, no mesmo ano, calculado com base no FINBRA e na base de dados do MEC. Para realizar o cálculo das funções, com suas respectivas 10.157 DMUs, foi utilizado o software Frontier Analyst 4.1, do fabricante Banxia Software ${ }^{\circledR}$. Posteriormente, a sequência envolve o cálculo da fronteira de eficiência na qual se localizam as escolas eficientes e, nessa fronteira, foram identificadas sete escolas. As escolas ineficientes estão localizadas sob essa curva. Os resultados obtidos pela técnica DEA e a fronteira de eficiência podem ser observados nas Figuras 2 e 3, respectivamente.

Algumas informações importantes a se destacar na Figura 3 são que, primeiramente, as sete escolas consideradas eficientes encontram-se na fronteira de eficiência 


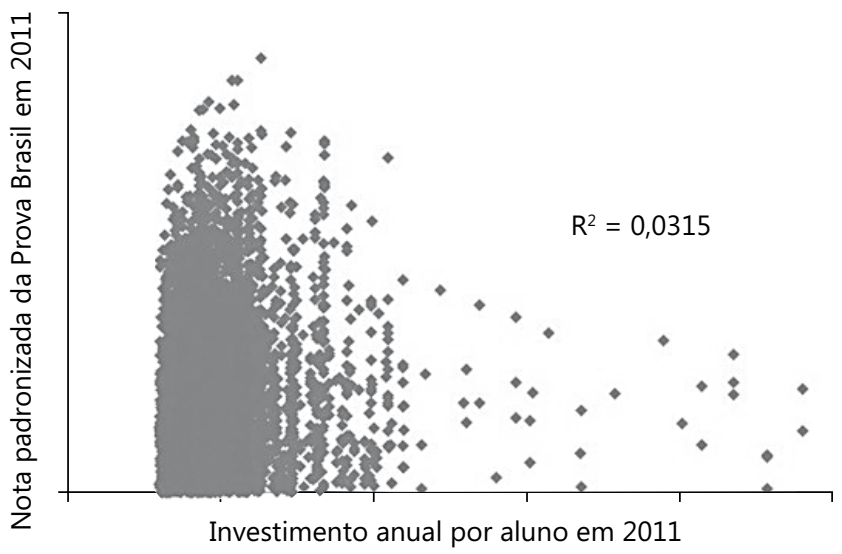

Fonte: Elaborado pelos autores (2013).

Figura 2. Dispersão com respectivo $R^{2}$ dos pontos gerados pelas duas variáveis analisadas nas 10.157 escolas municipais do ensino fundamental brasileiras do estudo.

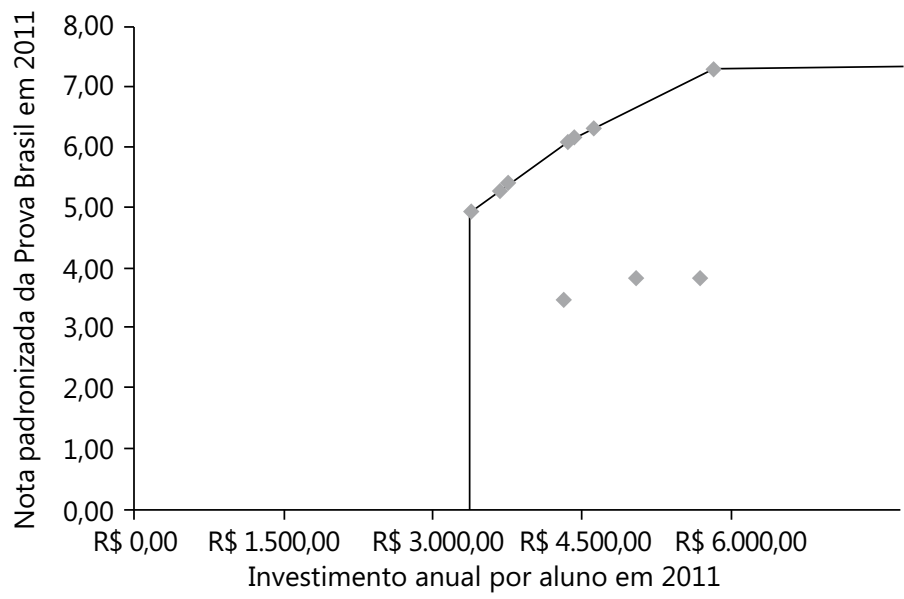

Fonte: Elaborado pelos autores (2013).

Figura 3. Fronteira de eficiência DEA onde se localizam as sete escolas consideradas eficientes e as três ineficientes utilizadas na pesquisa.

gerada a partir da análise DEA. A segunda informação é que todas as outras escolas, que estão localizadas sob a fronteira de eficiência, são consideradas ineficientes.

No intuito de analisar as sete escolas consideradas eficientes foi gerada, para melhor visualização e interpretação, a Tabela 1 . 
Tabela 1. Caracterização das sete escolas eficientes geradas pela técnica DEA.

\begin{tabular}{|c|c|c|c|c|c|c|c|}
\hline Escola & $\begin{array}{l}\text { Número } \\
\text { alunos na } \\
\text { escola }\end{array}$ & $\begin{array}{c}\text { Número de } \\
\text { Habitantes no } \\
\text { Município }\end{array}$ & $\begin{array}{c}\text { UF do I } \\
\text { Município }\end{array}$ & $\begin{array}{l}\text { Investimento } \\
\text { Anual } 2011\end{array}$ & $\begin{array}{c}\text { Nota } \\
\text { padronizada } \\
\text { na Prova Brasil }\end{array}$ & $\begin{array}{c}\text { Indicador } \\
\text { Rendimento }\end{array}$ & IDEB \\
\hline A & 208 & 9.368 & SP & $\mathrm{R} \$ 3.733,10$ & 5,38 & 0,98 & 5,25 \\
\hline B & 234 & 24.699 & RJ & $\mathrm{R} \$ 5.810,02$ & 7,30 & 0,91 & 6,63 \\
\hline C & 596 & 5.802 & MG & $\mathrm{R} \$ 4.367,42$ & 6,09 & 0,88 & 5,35 \\
\hline D & 302 & 6.066 & RS & $\mathrm{R} \$ 4.604,13$ & 6,30 & 0,71 & 4,50 \\
\hline$E$ & 297 & 6.873 & RS & $\mathrm{R} \$ 3.372,92$ & 4,94 & 0,96 & 4,76 \\
\hline $\mathrm{F}$ & 259 & 5.473 & RS & $R \$ 3.662,26$ & 5,29 & 0,89 & 4,69 \\
\hline G & 315 & 6.574 & RS & $\mathrm{R} \$ 4.404,68$ & 6,12 & 0,96 & 5,85 \\
\hline
\end{tabular}

Fonte: Elaborada pelos autores (2013).

Foram também analisadas algumas escolas consideradas ineficientes (considerouse aquelas com score DEA abaixo de 0,60 - em uma escala de 0 a 1), por meio de estudo de caso e que serviram como grupo de controle.

A seleção destas escolas ineficientes foi realizada no intuito de identificar aquelas com os fatores investimento por aluno, NSE, tamanho e localização, similares aos das escolas eficientes.

Desta forma, as escolas ineficientes devem estar localizadas nos estados de São Paulo, Rio de Janeiro, Minas Gerais e/ou Rio Grande do Sul e, em municípios com o número de habitantes entre 5 a 25 mil. Além disso, devem ser de tamanho médio, conforme classificação do Inep (2005), que define escola de tamanho médio entre 200 e 999 alunos.

Com relação ao NSE, é importante que ele seja similar nos dois grupos de escolas, pois não se deve comparar escolas de NSE diferentes (ALVES; SOARES, 2013; SAMMONS, 2008; COLEMAN et al., 1966; FREITAS, 2007; GREMAUD; FELÍCIO; BIONDI, 2007; SAMMONS, 2008). A heterogeneidade na escola e seu impacto sobre o desempenho dos alunos pode ser benéfica, de acordo com as pesquisas de Franco et al. (2007).

Portanto, foram escolhidas escolas ineficientes com NSE semelhantes aos das escolas eficientes, segundo classificação de Alves e Soares (2009). A Tabela 2 sintetiza as escolas ineficientes selecionadas, além de suas características. 
Tabela 2. Categorização das três escolas ineficientes selecionadas.

\begin{tabular}{|c|c|c|c|c|c|c|c|}
\hline Escola & $\begin{array}{c}\text { Número } \\
\text { alunos na } \\
\text { escola }\end{array}$ & $\begin{array}{c}\text { Número de } \\
\text { Habitantes no } \\
\text { Município }\end{array}$ & $\begin{array}{l}\text { UF do } \\
\text { Município }\end{array}$ & $\begin{array}{l}\text { Investimento } \\
\text { Anual } 2011\end{array}$ & $\begin{array}{c}\text { Nota } \\
\text { padronizada } \\
\text { na Prova Brasil }\end{array}$ & $\begin{array}{l}\text { Indicador } \\
\text { Rendimento }\end{array}$ & IDEB \\
\hline $\mathrm{H}$ & 370 & 15.731 & SP & $R \$ 5.030,89$ & 3,83 & 0,91 & 3,49 \\
\hline I & 489 & 13.728 & SP & $\mathrm{R} \$ 4.321,21$ & 3,46 & 0,90 & 3,13 \\
\hline J & 205 & 19.364 & RS & $R \$ 5.680,25$ & 3,82 & 0,75 & 2,85 \\
\hline
\end{tabular}

Fonte: Elaborada pelos autores (2013).

\subsection{Comparação entre as escolas eficientes, ineficientes e a população de todas as DMUs}

Para a caracterização das escolas eficientes, ineficientes e sua comparação com a população de todas as DMUs (10.157 escolas), foram geradas as informações descritas na Tabela 3, onde diferenças entre as médias das sete escolas eficientes, das três ineficientes e da população total das DMUs podem ser observadas. Essas diferenças estão relacionadas ao número de habitantes, localização geográfica, investimento anual por aluno, investimento máximo e mínimo, nota na Prova Brasil, indicador de rendimento e Ideb.

Destaca-se que as escolas eficientes comparadas à população possuem investimento menor e nota na Prova Brasil maior. Essa informação é coerente, pois se espera que as escolas eficientes obtenham nota maior na Prova Brasil com o mesmo valor obtido (em função da orientação DEA à output).

Outra informação relevante é que as escolas eficientes possuem indicador de rendimento acima da média da população, pois as escolas eficientes reprovam e/ou perdem seus alunos por evasão em menor quantidade que as escolas ineficientes. Consequentemente, a nota do Ideb, que é o produto do indicador de rendimento pela Prova Brasil, será maior nas escolas eficientes.

As diferenças encontradas entre as escolas eficientes e ineficientes é que, nestas, o investimento anual médio, em 2011, foi de $\mathrm{R} \$ 5.010,78$ contra $\mathrm{R} \$ 4.279,22$ das eficientes e R $\$ 4.695,83$ da população. Destaque para o fato de que todas as escolas encontram-se acima do valor mínimo recomendado pelo Custo Aluno-Qualidade inicial (CAQi). 
Tabela 3. Indicadores de todas as escolas municipais do ensino fundamental consideradas no estudo, dos sete municípios eficientes definidos pela análise DEA e das três ineficientes selecionadas segundo critérios.

\begin{tabular}{|c|c|c|c|}
\hline & População & Escolas Eficientes & Escolas Ineficientes \\
\hline Número de escolas & 10.157 & 7 & 3 \\
\hline Localização & Brasil & $M G, R J, R S$ e $S P$ & RS e SP \\
\hline $\begin{array}{l}\text { Tamanho dos municipios } \\
\text { (habitantes) }\end{array}$ & Todos & até 25.000 & até 20.000 \\
\hline $\begin{array}{l}\text { Nível socioeconomico (NSE) } \\
\text { (ALVES e SOARES,2009) }\end{array}$ & $\begin{array}{l}\text { Mais baixo (1) } \\
\text { à Mais alto (7) }\end{array}$ & $\begin{array}{l}\text { Médio (4) e } \\
\text { Médio-alto (5) }\end{array}$ & Médio (4) \\
\hline Investimento anual médio por aluno & $R \$ 4.695,83$ & $R \$ 4.279,22$ & $R \$ 5.010,78$ \\
\hline $\begin{array}{l}\text { Investimento anual médio por } \\
\text { aluno (desvio-padrão) }\end{array}$ & $\mathrm{R} \$ 1.667,34$ & $R \$ 753,34$ & $\mathrm{R} \$ 555,01$ \\
\hline $\begin{array}{l}\text { Menor Investimento anual médio } \\
\text { por aluno }\end{array}$ & $R \$ 3.350,29$ & $\mathrm{R} \$ 3.372,92$ & $\mathrm{R} \$ 4.321,21$ \\
\hline $\begin{array}{l}\text { Maior Investimento anual médio } \\
\text { por aluno }\end{array}$ & $\mathrm{R} \$ 24.330,70$ & $\mathrm{R} \$ 5.810,02$ & $R \$ 5.680,25$ \\
\hline $\begin{array}{l}\text { CAQI (Custo Aluno Qualidade } \\
\text { Inicial) (ARAUJO, 2012) }\end{array}$ & $\mathrm{R} \$ 3.047,00$ & $\mathrm{R} \$ 3.047,00$ & $\mathrm{R} \$ 3.047,00$ \\
\hline Média Prova Brasil Padronizada & 4,61 & 5,92 & 3,70 \\
\hline $\begin{array}{l}\text { Média Prova Brasil Padronizada } \\
\text { (desvio-padrão) }\end{array}$ & 0,74 & 0,73 & 0,17 \\
\hline Média Indicador de rendimento & 0,83 & 0,90 & 0,85 \\
\hline $\begin{array}{l}\text { Média Indicador de rendimento } \\
\text { (desvio-padrão) }\end{array}$ & 0,11 & 0,69 & 0,07 \\
\hline Média IDEB & 3,81 & 5,29 & 3,16 \\
\hline Média IDEB (desvio-padrão) & 0,89 & 0,03 & 0,26 \\
\hline
\end{tabular}

Fonte: Elaborada pelos autores (2013).

Nas escolas ineficientes a média na nota na Prova Brasil, em 2011, foi de 3,70 contra 5,92 das eficientes e 4,61 da população, ou seja, a menor dos três grupos. Dessa forma, as três escolas ineficientes da amostra são caracterizadas como aquelas que investem acima da média e obtém nota na Prova Brasil abaixo da média.

Complementarmente, pode ser observado também que as escolas ineficientes apresentam média de indicador de rendimento 0,85 contra 0,90 das eficientes e 0,83 da população e média de Ideb de 3,16 contra 5,29 das eficientes e 5,29 da população. 


\section{Aplicação da segunda fase da Metodologia de Salgado Junior e Novi: fase qualitativa}

Essa etapa é necessária para identificar e analisar os processos internos das escolas que podem colaborar para os resultados do desempenho dos alunos, pois, nas análises quantitativas eles são desconsiderados e, assim, elas permanecem como uma "caixa-preta" (LEE; BRYK; SMITH, 1993; SAMMONS; HILLMAN; MORTIMORE, 1995).

Nesta segunda etapa, buscou-se identificar as práticas que estivessem ou não relacionadas aos investimentos financeiros e que também pudessem, de alguma forma, contribuir para o desempenho dos alunos. Para tanto, foram realizados estudos de caso em profundidade nas escolas, por meio de entrevistas semiestruturadas com diretores, secretárias municipais da educação, professores, alunos e pais de alunos.

Esta segunda etapa da metodologia de Salgado Junior e Novi (2014) corrobora com os estudos de Lareau (1989), que sugere que a investigação qualitativa tenta preencher os "espaços vazios" deixados pelos modelos estatísticos, procurando compreender como as ações individuais são socialmente condicionadas, mas sem figurar uma abordagem psicológica. Assim, os dados quantitativos e os dados qualitativos produzem descrições da realidade que são igualmente ricos, mas que se diferenciam pelo grau de proximidade (GAME, 2002).

Para a identificação das práticas que podem influenciar no desempenho dos alunos, foi realizada por Salgado Junior e Novi (2014) uma pesquisa na literatura sobre o tema, além de ter sido conseguida uma entrevista, não estruturada, com uma diretora de escola e ex-secretária da educação, com o objetivo de confrontar as variáveis identificadas na literatura com as práticas pedagógicas.

Dessa forma, as variáveis para o estudo foram divididas em "gestão e destinação dos recursos financeiros" e "pedagógicas e socioeconômicas", conforme consta na metodologia, onde as variáveis são as práticas administrativo-pedagógicas mais influentes para o desempenho dos alunos na Prova Brasil. Essas variáveis serviram de apoio para o desenvolvimento dos roteiros de entrevistas semiestruturados que, posteriormente, foram aplicados aos estudos de múltiplos caso nas escolas eficientes e nas ineficientes. As variáveis independentes são classificadas em dois grupos em função de suas características predominantes (BROOKE, 2008).

Em relação ao grupo em que cada variável deveria estar, foi realizado por Salgado Junior e Novi (2014) uma classificação como atividade ou fator de influência, 
com base em literatura pesquisada. Para Saraiva e Wagner (2013, p. 767), “É necessário que cada instituição, de acordo com suas características e condições, faça um esforço para sistematizar estratégias conjuntas [...]”.

Sendo assim, para aplicar a segunda etapa da metodologia de Salgado Junior e Novi (2014), foram desenvolvidas as seguintes atividades:

1. Realizar estudo de múltiplos casos nas escolas eficientes e ineficientes, com o objetivo de identificar práticas administrativo-pedagógicas que possam contribuir para o desempenho dos alunos: $O$ objetivo nesta atividade foi identificar práticas administrativo-pedagógicas internas aos processos escolares que possam influenciar para que, escolas com investimentos, NSE e tamanho similares a outras, tenham desempenho superior de seus alunos na Prova Brasil. Nos estudos de caso realizados, essas práticas foram identificadas por meio de entrevistas semiestruturadas com secretários da educação, diretores, professores, alunos e pais de alunos. Foram abordadas questões sobre, por exemplo, a influência da família, leitura, disciplina, infraestrutura, aplicação dos recursos financeiros, reprovação, rotatividade de professores, etc. Isso porque, conforme consta na literatura, além do investimento financeiro, outras variáveis independentes (práticas) também podem influenciar no desempenho dos alunos (SALGADO JUNIOR; NOVI, 2013).

2. Comparar, nas escolas eficientes e ineficientes, a frequência com que as práticas administrativo-pedagógicas, que podem influenciar no desempenho dos alunos, foram identificadas: Inicialmente, utilizou-se quadros contendo as práticas que podem influenciar no desempenho dos alunos, com base na metodologia de Salgado Junior e Novi (2014), que buscou respaldo na literatura pesquisada sobre o tema. Apesar de Soares et al. (2002) ressaltarem que a literatura não separa a figura da liderança administrativa e financeira da liderança pedagógica, nos estudos de caso, é importante verificar, isoladamente, a frequência com que as práticas foram ou não identificadas nas escolas. Ou melhor, ao final dos estudos de caso é possível mensurar a frequência de cada prática, em cada uma das escolas eficientes e ineficientes. Por exemplo, se a prática for encontrada frequentemente nas escolas eficientes e, de forma esporádica, nas ineficientes (esta situação será definida como prática, significativamente diferente), aumenta-se a possibilidade de que essa prática possa influenciar no desempenho dos alunos, considerando o grupo de escolas estudadas. Dessa forma, coube aos pesquisadores definirem o limite em que a frequência do grupo estudado seja, significativamente, diferente entre as escolas eficientes e ineficientes. Por fim, é importante destacar que existe um aumento na possibilidade da prática influenciar no desempenho 
dos alunos quando ela for classificada como significativamente diferente, entre os dois grupos de escolas. No entanto, não será possível afirmar que ela realmente é a mais influente no desempenho dos alunos, uma vez que se trabalha com estudos de caso em amostra não representativa da população. Por outro lado, resultados mais precisos podem ser obtidos a medida em que se aumenta o número de escolas a serem estudadas. Salgado Junior e Novi (2014) pesquisaram na literatura estudos convergentes e divergentes de seus resultados.

\section{Análise dos resultados nas escolas eficientes e ineficientes: práticas identificadas frente aos estudos encontrados na literatura por Salgado Junior e Novi}

A apresentação e análise dos resultados encontrados nos estudos de caso das escolas eficientes e ineficientes, identificados por meio dos indicadores propostos da metodologia de Salgado Junior e Novi (2014), foi feita por meio de Quadros. Assim, foi verificada a frequência na qual cada uma das práticas, que compõe cada um dos indicadores (gestão e destinação dos recursos financeiros e as pedagógicas e socioeconômicas) foram encontradas em cada uma das escolas e Secretarias Municipais de Educação (SME).

Os resultados foram comparados por meio da frequência na qual essas práticas foram identificadas nas escolas eficientes e ineficientes. Salgado Junior e Novi (2014) pesquisaram na literatura estudos convergentes e divergentes de seus resultados, concluindo que uma prática não pode ser considerada como o responsável pelo desempenho dos alunos. Além disso, não se pode generalizálas, pois foram realizados estudos de caso em dez escolas.

É importante destacar que existe um aumento na possibilidade da prática influenciar no desempenho dos alunos quando ela for classificada como significativamente diferente, entre o grupo de escolas eficientes e ineficientes. Contudo, segundo Salgado Junior e Novi (2014), não será possível afirmar que ela realmente é a prática mais influente no desempenho dos alunos, uma vez que, na literatura, estudos que convergem ou divergem desses resultados foram encontrados.

A influência da prática no desempenho do aluno na Prova Brasil aumenta à medida em que há um incremento na diferença da frequência encontrada, pela mesma prática, nas escolas eficientes e ineficientes. Por outro lado, quando essa diferença é pequena, a tendência é que a influência dessa prática no desempenho do aluno seja reduzida, uma vez que ela tem menor poder para explicar como as 
escolas com condições similares (de investimentos financeiros, NSE, tamanho, etc.), podem obter resultados diferentes na Prova Brasil.

Segundo critério de julgamento, foi definido o limite que torna a diferença entre os dois grupos de escolas relevante, todavia, esse limite não é conceitual, podendo ser questionado e redefinido por outro pesquisador que deseje refazer este estudo, aplicando esta metodologia no mesmo ou em outro universo de escolas.

Dessa forma, neste estudo, que possui um grupo formado por sete escolas eficientes e três ineficientes, o critério para definir uma diferença significativa da influência da prática no desempenho do aluno será de acordo com a proposta pela metodologia de Salgado Junior e Novi (2014).

A regra para se considerar uma diferença significativa entre a frequência da prática encontrada na escola eficiente e ineficiente é: quando a prática foi observada em, no máximo, uma escola ineficiente e, no mínimo, em cinco escolas eficientes; se um dos critérios não for atingido, a diferença não será considerada significativa para este estudo. Ademais, foram destacadas as práticas que aparecem com frequência máxima em um dos grupos e mínima, no outro grupo de escolas.

\section{Análise da comparação por indicadores pedagógicos e socioeconômicos e por indicadores de gestão e destinação dos recursos}

Nos Quadros 1 e 2 é possível verificar a frequência das práticas que caracterizam cada indicador pedagógico e socioeconômico e cada indicador gestão e destinação dos recursos identificadas nas escolas eficientes e ineficientes. Essas práticas estão elencadas nesses quadros, na coluna "descrição atividade". Elas foram encontradas nessas escolas e colaboram na formação de cada indicador. Os resultados dos estudos de caso foram comparados à literatura pesquisada por Salgado Junior e Novi (2014). Os pesquisadores destacam para cada prática as principais convergências e divergências entre os resultados encontrados em seu estudo e a percepção dos autores. Assim, nesta pesquisa, a análise e comparação das práticas foi realizada, no intuito de se destacar aquelas com diferença significativa na frequência entre ambas as escolas.

Apesar de existir uma limitação em se estudar, por meio de estudo de caso, um número maior de escolas eficientes do que aquelas localizadas na fronteira de eficiência, tal fato se dá em decorrência da técnica DEA utilizada na primeira etapa da metodologia, geralmente, restringir o número dessas escolas. Entretanto, 


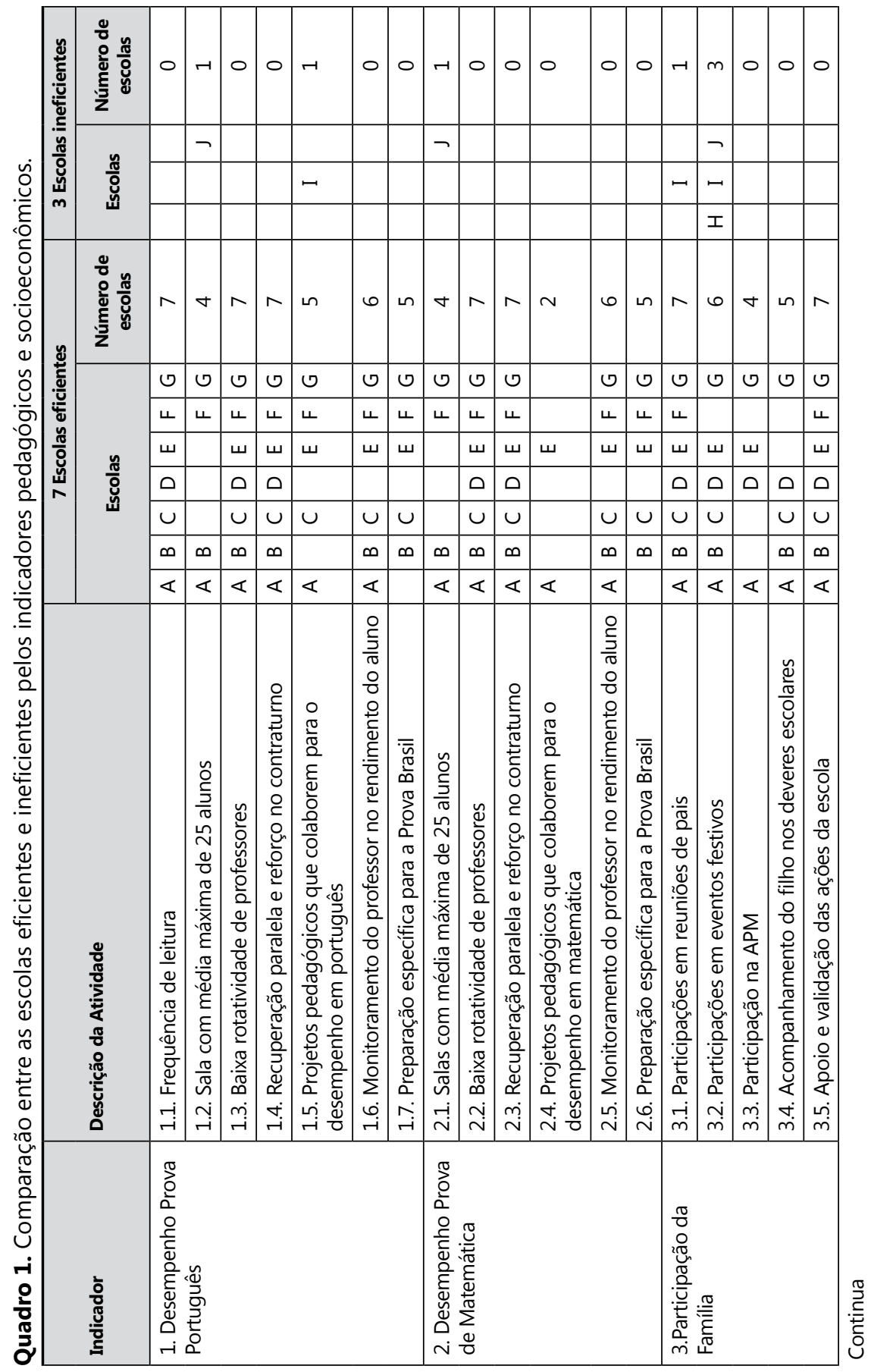




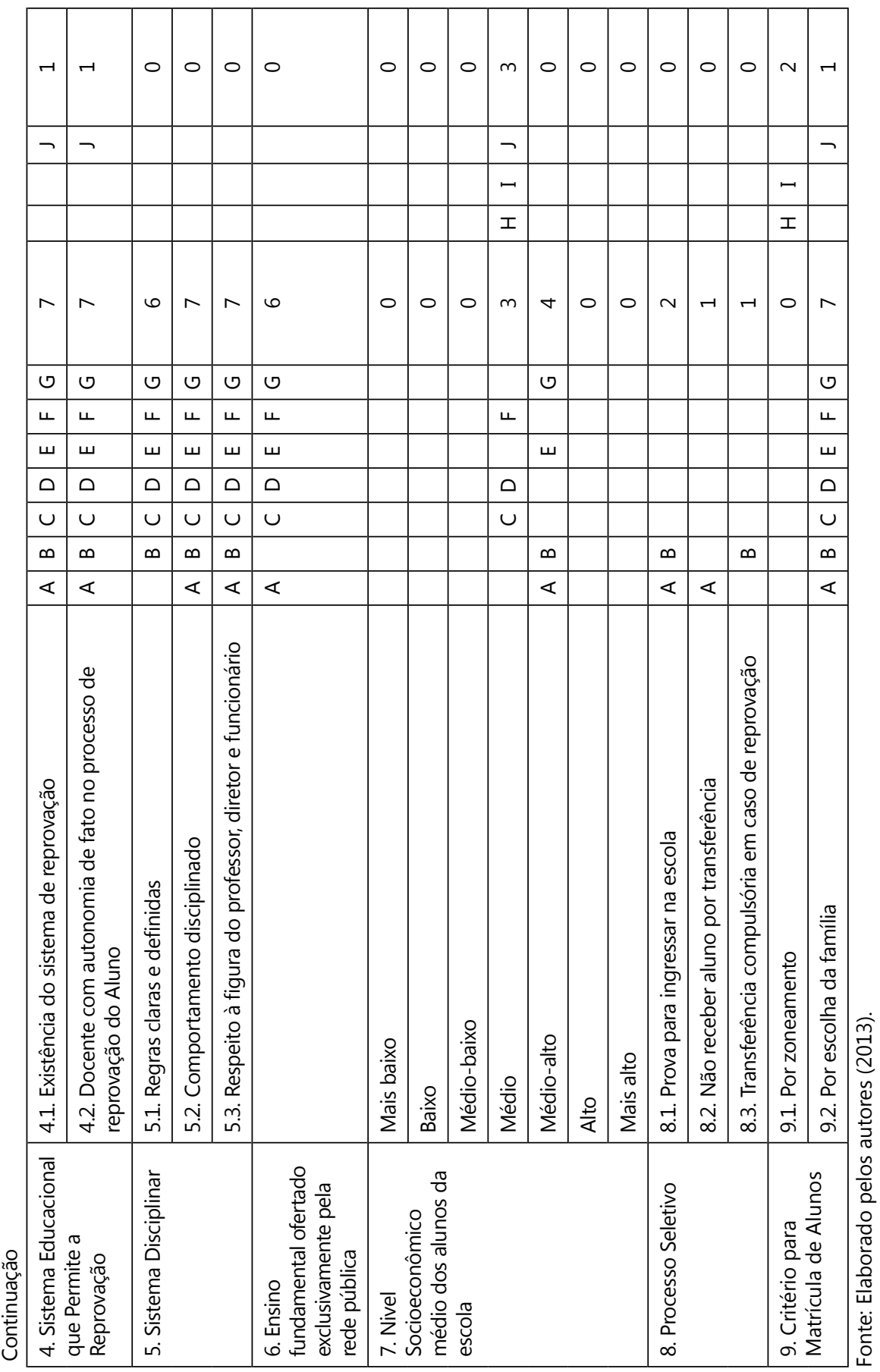




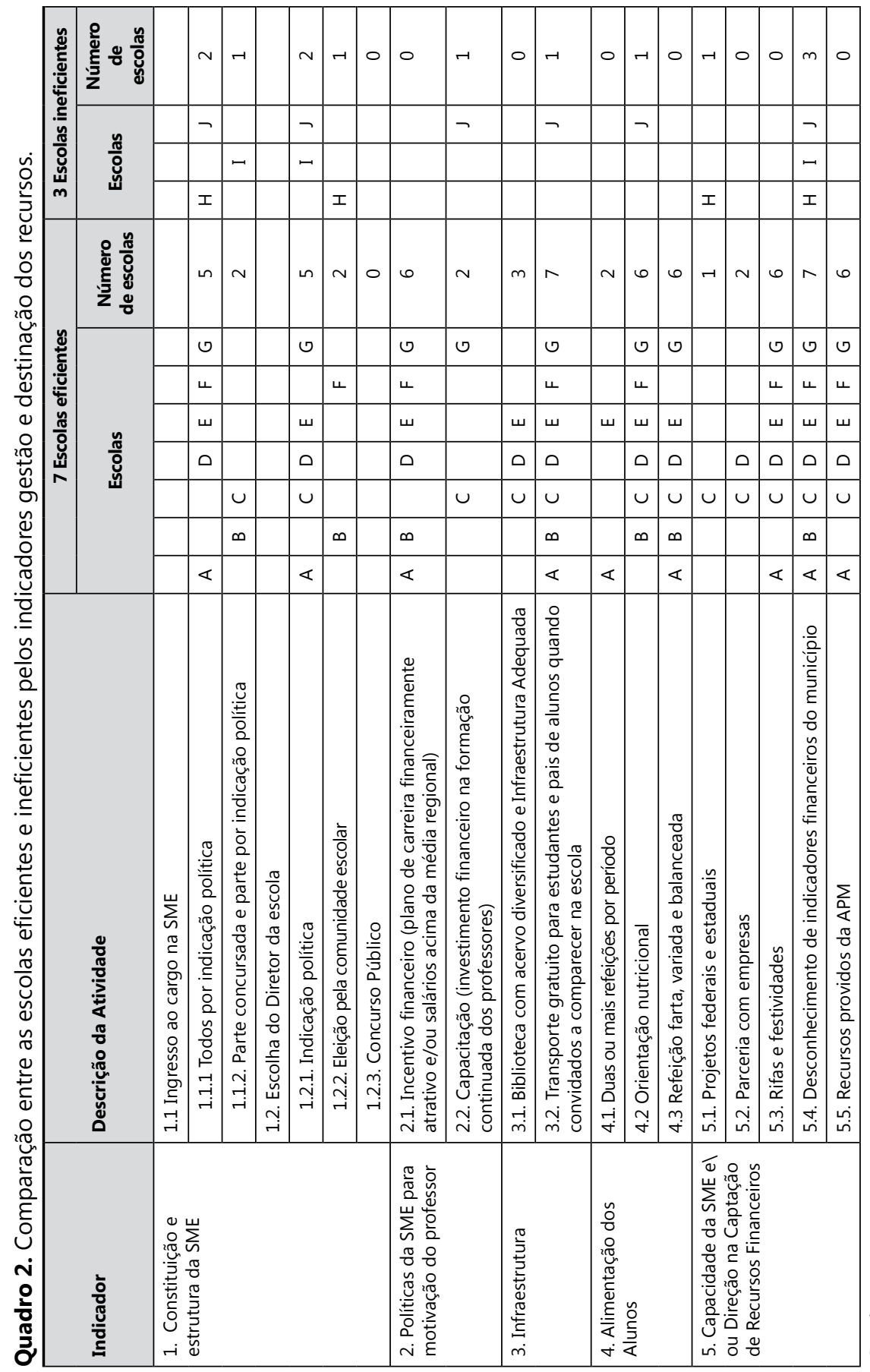




\begin{tabular}{|c|c|c|c|c|c|c|c|c|c|c|c|c|c|}
\hline 0 & 0 & $\sim$ & $m$ & $m$ & $m$ & $m$ & 0 & $r$ & 0 & $m$ & 0 & 0 & $\sim$ \\
\hline & & $\neg$ & $\neg$ & $\neg$ & $\neg$ & $\neg$ & & & & $\neg$ & & & $\neg$ \\
\hline & & & $\varpi$ & $\varpi$ & $\varpi$ & - & & & & $\varpi$ & & & \\
\hline & & $I$ & $I$ & $I$ & $I$ & I & & I & & $I$ & & & I \\
\hline \multirow[t]{2}{*}{$r$} & $r$ & $\wedge$ & $\wedge$ & 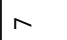 & 0 & $r$ & in & 0 & 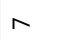 & in & 0 & 0 & $-r$ \\
\hline & & ৩ & ৩ & ৩ & & & & & ৩ & $\cup$ & & & ৩ \\
\hline \multirow[t]{6}{*}{ ५ } & 4 & ४ & L & ᄂ & & & ए & & L & & & & \\
\hline & & ш & س & س & & & ш & & س & س & & & \\
\hline & & ○ & O & 0 & & & 口 & & 0 & D & & & \\
\hline & & $\cup$ & $\cup$ & $u$ & & $\cup$ & $\cup$ & & $\cup$ & $\cup$ & & & \\
\hline & & $\infty$ & $\infty$ & $\infty$ & & & & & $\infty$ & & & & \\
\hline & & $\varangle$ & $\varangle$ & $\varangle$ & & & $\varangle$ & & $\varangle$ & $\varangle$ & & & \\
\hline 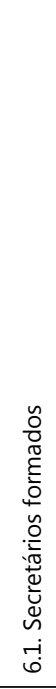 & 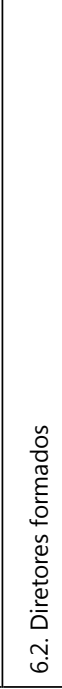 & 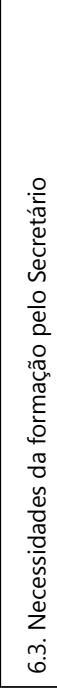 & 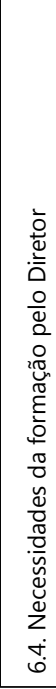 & 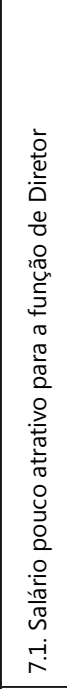 & 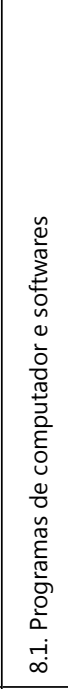 & 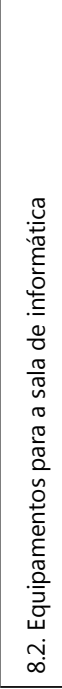 & 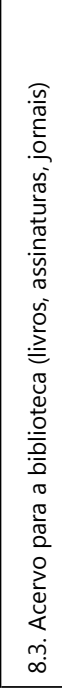 & 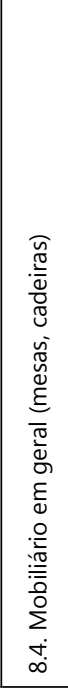 & 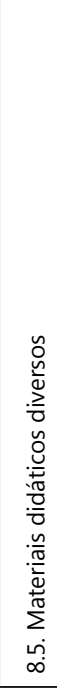 & 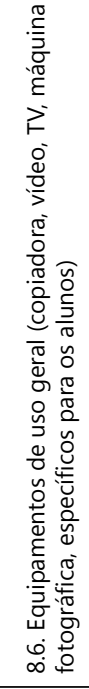 & 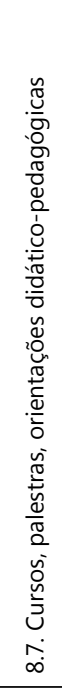 & 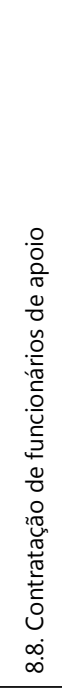 & 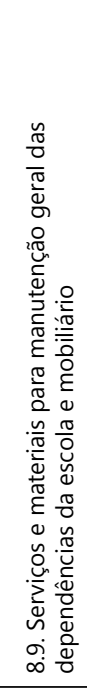 \\
\hline \multicolumn{4}{|l|}{ 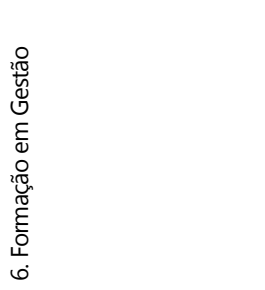 } & 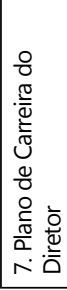 & 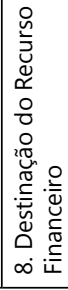 & & & & & & & & \\
\hline
\end{tabular}


as possibilidades de escolha das escolas ineficientes são maiores em função do seu próprio universo.

É importante destacar que as práticas, que são consideradas sem diferença significativa, também podem influenciar no desempenho. Entretanto, para o grupo de escolas estudadas, o nível de diferença significativa definida na pesquisa e, dentro da técnica DEA proposta, aparentemente, apresentam menor influência no desempenho dos alunos.

Para melhor compreender esses resultados, foram analisados os processos internos das escolas pesquisadas, no que se refere à frequência em que cada uma das práticas foram identificadas, por meio da metodologia de Salgado Junior e Novi (2014).

Dessa forma, as práticas com diferença significativa referentes à variável gestão e destinação dos recursos e pedagógico e socioeconômico são destacadas e apresentadas nos Quadros 3 e 4 . Nesses quadros, as práticas estão elencadas na coluna "descrição atividade".

Sendo assim, foram identificadas 26 práticas administrativo-pedagógicas como significativamente relevantes para o desempenho, na Prova Brasil 2011, dos alunos das escolas municipais do ensino fundamental, conforme Quadros 3 e 4. Essas práticas foram encontradas com maior frequência em um grupo de escolas e, provavelmente, podem ter uma maior influência nos resultados de desempenho desses alunos. Elas estão elencadas a seguir:

\section{Práticas administrativas com diferença significativa relacionadas ao indicador gestão e destinação dos recursos:}

1. Incentivo financeiro (plano de carreira financeiramente atrativo e/ou salários acima da média regional)

2. Transporte gratuito para estudantes e pais de alunos quando convidados a comparecer à escola

3. Orientação nutricional

4. Refeição farta, variada e balanceada

5. Rifas e festividades

6. Recursos providos da APM

7. Programas de computador e software

8. Equipamentos para sala de informática

9. Acervo para a biblioteca (livros, assinaturas, jornais)

10. Materiais didáticos diversos 
Quadro 3. Práticas com diferença significativa entre as atividades referentes aos indicadores gestão e destinação dos recursos das escolas eficientes e ineficientes.

\begin{tabular}{|c|c|c|c|c|c|c|c|c|c|c|c|c|c|}
\hline \multirow{3}{*}{$\begin{array}{l}\text { Indicador } \\
\text { 2. Políticas } \\
\text { da SME para } \\
\text { motivação do } \\
\text { professor }\end{array}$} & \multirow{3}{*}{\begin{tabular}{|l|} 
Descrição da Atividade \\
$\begin{array}{l}\text { 2.1. Incentivo financeiro } \\
\text { (plano de carreira } \\
\text { financeiramente } \\
\text { atrativo e/ou salários } \\
\text { acima da média } \\
\text { regional) }\end{array}$ \\
\end{tabular}} & \multicolumn{8}{|c|}{7 Escolas eficientes } & \multicolumn{4}{|c|}{3 Escolas ineficiente } \\
\hline & & \multicolumn{7}{|c|}{ Escolas } & \multirow{2}{*}{\begin{tabular}{|c|}
$\begin{array}{c}\text { Número } \\
\text { de escolas }\end{array}$ \\
6
\end{tabular}} & \multicolumn{3}{|c|}{ Escolas } & \multirow{2}{*}{$\begin{array}{c}\begin{array}{c}\text { Número } \\
\text { de } \\
\text { escolas }\end{array} \\
0\end{array}$} \\
\hline & & $A$ & B & & $\mathrm{D}$ & $E$ & $\mathrm{~F}$ & G & & & & & \\
\hline $\begin{array}{l}3 . \\
\text { Infraestrutura }\end{array}$ & $\begin{array}{l}\text { 3.2. Transporte } \\
\text { gratuito para } \\
\text { estudantes e pais } \\
\text { de alunos quando } \\
\text { convidados a } \\
\text { comparecer na escola }\end{array}$ & A & B & $C$ & D & $E$ & $\mathrm{~F}$ & G & 7 & & & $J$ & 1 \\
\hline \multirow[t]{2}{*}{$\begin{array}{l}\text { 4. Alimentação } \\
\text { dos Alunos }\end{array}$} & $\begin{array}{l}4.2 \text { Orientação } \\
\text { nutricional }\end{array}$ & & B & $C$ & D & $E$ & $\mathrm{~F}$ & G & 6 & & & J & 1 \\
\hline & $\begin{array}{l}4.3 \text { Refeição farta, } \\
\text { variada e balanceada }\end{array}$ & A & B & $C$ & D & $\mathrm{E}$ & & G & 6 & & & & 0 \\
\hline \multirow{2}{*}{$\begin{array}{l}\text { 5. Capacidade } \\
\text { da SME elou } \\
\text { Direção na } \\
\text { Captação } \\
\text { de Recursos } \\
\text { Financeiros }\end{array}$} & $\begin{array}{l}\text { 5.3. Rifas e } \\
\text { festividades }\end{array}$ & $A$ & & $C$ & D & $\mathrm{E}$ & $F$ & G & 6 & & & & 0 \\
\hline & $\begin{array}{l}\text { 5.5. Recursos providos } \\
\text { da APM }\end{array}$ & $A$ & & $C$ & $D$ & $E$ & $F$ & G & 6 & & & & 0 \\
\hline \multirow[t]{4}{*}{$\begin{array}{l}\text { 8. Destinação } \\
\text { do Recurso } \\
\text { Financeiro }\end{array}$} & $\begin{array}{l}\text { 8.1. Programas } \\
\text { de computador e } \\
\text { softwares }\end{array}$ & & & & & & & & 0 & $\mathrm{H}$ & I & J & 3 \\
\hline & $\begin{array}{l}\text { 8.2. Equipamentos } \\
\text { para a sala de } \\
\text { informática }\end{array}$ & & & C & & & & & 1 & $\mathrm{H}$ & I & J & 3 \\
\hline & $\begin{array}{l}\text { 8.3. Acervo para a } \\
\text { biblioteca (livros, } \\
\text { assinaturas, jornais) }\end{array}$ & A & & $C$ & $D$ & $\mathrm{E}$ & $F$ & & 5 & & & & 0 \\
\hline & $\begin{array}{l}\text { 8.5. Materiais } \\
\text { didáticos diversos }\end{array}$ & A & B & $C$ & D & $E$ & $F$ & G & 7 & & & & 0 \\
\hline
\end{tabular}

Fonte: Elaborado pelos autores (2013). 


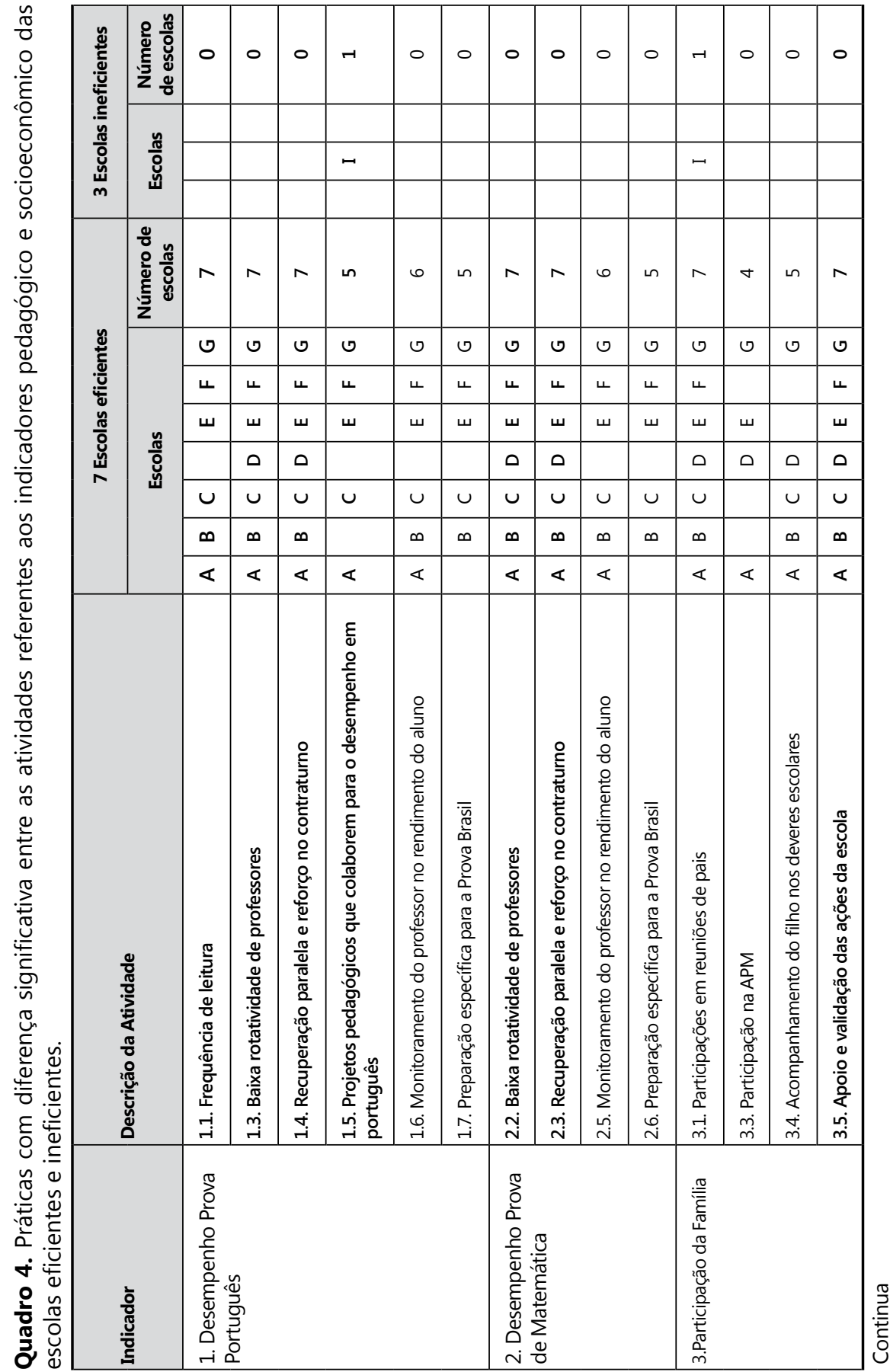




\begin{tabular}{|c|c|c|c|c|c|c|c|c|c|c|c|}
\hline 0 & 0 & 0 & 0 & 0 & 0 & 0 & $m$ & 0 & 0 & 0 & $r$ \\
\hline & & & & & & & $\neg$ & & & & $\neg$ \\
\hline & & & & & & & • & & & & \\
\hline & & & & & & & I & & & & \\
\hline 0 & 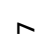 & 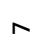 & 0 & 0 & 0 & 0 & $m$ & $\sigma$ & 0 & 0 & $\Lambda$ \\
\hline ৩ & ט & ט & ৩ & & & & & ৩ & & & ৩ \\
\hline 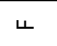 & 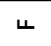 & 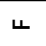 & ᄂ & & & & ᄂ & & & & ப \\
\hline ш & س & س & س & & & & & س & & & س \\
\hline 0 & 0 & 0 & ص & & & & ص & & & & ص \\
\hline$u$ & $u$ & $u$ & $\cup$ & & & & $u$ & & & & $\cup$ \\
\hline$\infty$ & $\infty$ & $\infty$ & & & & & & 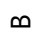 & & & $\varpi$ \\
\hline & $\varangle$ & $\varangle$ & $\varangle$ & & & & & $\varangle$ & & & $\ll$ \\
\hline 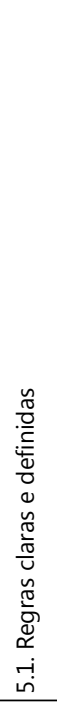 & 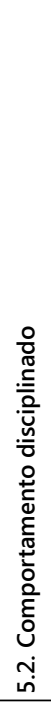 & 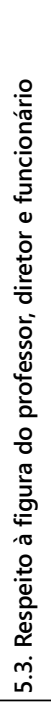 & & $\begin{array}{l}\frac{\Omega}{x} \\
\frac{\pi}{\pi} \\
. \frac{n}{\pi} \\
\sum\end{array}$ & 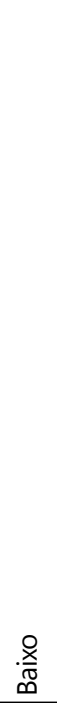 & 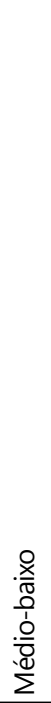 & $\begin{array}{l}\frac{0}{2} \\
\stackrel{\mathbb{d}}{\Sigma}\end{array}$ & 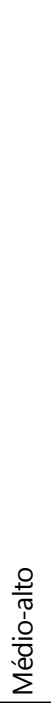 & $\frac{\text { 운 }}{2}$ & $\begin{array}{l}\frac{0}{ \pm} \\
\frac{ \pm}{\pi} \\
\frac{n}{\pi} \\
\sum\end{array}$ & 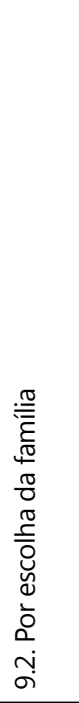 \\
\hline 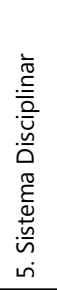 & & & 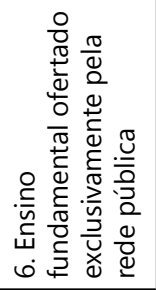 & $\stackrel{\Phi}{\Sigma}$ & 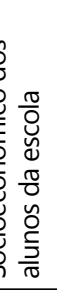 & & & & & & 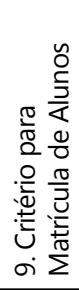 \\
\hline
\end{tabular}




\section{Práticas pedagógicas com diferença significativa relacionadas ao indicador pedagógico e socioeconômico:}

11. Frequência de leitura

12. Baixa rotatividade de professores

13. Recuperação paralela e reforço no contraturno

14. Projetos pedagógicos que colaborem para o desempenho em português

15. Monitoramento do professor no rendimento do aluno

16. Participações em reuniões de pais, participação na APM

17. Acompanhamento do filho nos deveres escolares

18. Apoio e validação das ações da escola

19. Existência do sistema de reprovação

20. Docente com autonomia de fato no processo de reprovação do aluno

21. Ensino fundamental ofertado exclusivamente pela rede pública

22. Nível socioeconômico médio dos alunos da escola (heterogeneidade)

23. Critério para matrícula de alunos: por escolha da família

24. Regras claras e definidas

25. Comportamento disciplinado

26. Respeito à figura do professor, diretor e funcionário

\section{Conclusão}

Em síntese, as pesquisas realizadas no intuito de se identificar práticas que possam influenciar no desempenho dos alunos não utilizaram escolas pertencentes a grupos similares, que tivessem diferentes desempenhos explicados pelo efeito das escolas ou das práticas a elas associadas. Nesse sentido, o objetivo do presente estudo foi aplicar a metodologia de Salgado Junior e Novi (2014) para identificar práticas administrativo-pedagógicas que possam contribuir para o desempenho dos alunos de escolas municipais do ensino fundamental na Prova Brasil.

Dentre as dez escolas envolvidas nos estudos de caso realizados, sete são consideradas eficientes, calculadas na fronteira DEA, e três são consideradas ineficientes, escolhidas por julgamento e conveniência. Portanto, destaca-se a importância da presente pesquisa em relação à identificação das melhores práticas mediante a aplicação dessa proposta metodológica, no intuito de compreender os processos internos escolares que apresentam similaridades, mas desempenhos diferentes na Prova Brasil.

Com base nos resultados obtidos pela aplicação da metodologia, conclui-se que foi possível identificar evidências de que 26 práticas administrativo-pedagógicas contribuíram para o desempenho dos alunos de escolas municipais do ensino fundamental na Prova Brasil, no ano de 2011. 
Sendo assim, espera-se poder auxiliar no processo de melhoria da qualidade educacional, políticas públicas e gestão dos recursos para a Educação no país.

\section{Sugestões}

Existe um aumento na possibilidade dessas práticas identificadas neste estudo influenciarem no desempenho dos alunos quando elas forem classificadas como significativamente diferentes, entre o grupo de escolas eficientes e ineficientes. Assim, não será possível afirmar que determinada prática realmente é a mais influente no desempenho dos alunos, uma vez que se trabalha com estudos de caso em amostra não representativa da população, por isso não se pode generalizá-las.

Por outro lado, resultados mais precisos podem ser obtidos à medida em que se aumenta o número de escolas a serem estudadas. Dessa forma, diferentes práticas poderão ser encontradas caso essa metodologia seja aplicada em condições diferentes das testadas, pois ela, ao utilizar as abordagens quantitativa e qualitativa, se diferencia dos demais estudos anteriormente realizados.

\section{Agradecimentos}

Os autores agradecem o apoio da Coordenação de Aperfeiçoamento de Pessoal de Nível Superior (CAPES) em projeto contemplado pelo Programa Observatório da Educação da Capes (OBEDUC) para a elaboração desta pesquisa. 


\section{Administrative and pedagogical practices that can contribute to the performance of students in municipal elementary schools in Prova Brasil}

\section{Abstract}

This research aimed to apply the methodology developed by Salgado Junior (2013) to identify administrative and pedagogical practices that may help enhance the performance of municipal primary school students in Prova Brasil. Unlike previous related research, this methodology utilizes two approaches: qualitative and quantitative. At the first stage, which is quantitative and uses data envelopment analysis, seven efficient schools were compared to three inefficient schools; schools were selected according to judgment and convenience. At the second stage, which is qualitative, multiple case studies were conducted to understand the internal processes that drive schools with similar characteristics to deliver different performances. Consequently, evidence was found that 26 administrative and pedagogical practices may help enhance students' performance in Prova Brasil. These results are expected to assist in the process of improving educational quality, public policies, and resource management in education in Brazil.

Keywords: Elementary school. Prova Brasil. Data Envelopment Analysis (DEA). Efficiency and investment in education.

\section{Propuesta de prácticas administrativas y pedagógicas que pueden contribuir a mejorar el desempeño de los estudiantes en las escuelas primarias municipales en Prova Brasil}

\section{Resumen}

El objetivo de esta investigación fue aplicar la metodología de Salgado Junior (2013) para identificar las prácticas administrativas y pedagógicas que pueden contribuir a mejorar el desempeño de los estudiantes en las escuelas primarias municipales en Prova Brasil. A diferencia de los estudios previos relacionados con el tema, esta metodología se divide en una etapa cualitativa y otra cuantitativa. La primera etapa de carácter cuantitativo se compararon siete escuelas eficientes, calculadas en la frontera de análisis envolvente de datos (DEA) a tres escuelas ineficientes, elegidas por ensayo y conveniencia. En la segunda etapa, cualitativa, con el objetivo de comprender los procesos internos que llevan a escuelas similares a tener desempeños diferentes, se realizaron estudios de múltiples casos. Fue posible identificar evidencias de que 26 prácticas administrativas y pedagógicas pueden contribuir al desempeño de los estudiantes en Prova Brasil. Se espera poder ayudar a mejorar la calidad del proceso educativo, políticas públicas y la gestión de los recursos para la educación en el país.

Palabras clave: Educación primaria. Prova Brasil. Análisis Envolvente de Datos (DEA). Eficiencia e inversión en educación. 


\section{Referências}

ALVES, M. T. G.; SOARES, J. F. Contexto escolar e indicadores educacionais: condições desiguais para a efetivação de uma política de avaliação educacional. Educação e Pesquisa, São Paulo, v. 39, n. 1, p. 177-94, jan./mar. 2013. DOI: 10.1590/S1517-9702201300010001

. Medidas de nível socioeconômico em pesquisas sociais:

uma aplicação aos dados de uma pesquisa educacional. Opinião Pública, Campinas, v. 15, n. 1, p. 1-30, jun. 2009. DOI: 10.1590/S010462762009000100001

ANDRADE, E. C. Rankings em educação: tipos, problemas, informações e mudanças: Análise dos principais rankings oficiais brasileiros.

Estudos Econômicos, São Paulo, v. 41, n. 2, p. 323-43, abr./jun. 2011. DOI: $10.1590 / \mathrm{S} 0101-41612011000200005$

BARDIN, L. Análise de conteúdo. São Paulo: Edições 70, 2011.

BIONDI, R. L.; FELÍCIO, F. Atributos escolares e o desempenho dos estudantes: uma análise em painel dos dados Saeb. Brasília, DF: INEP, 2007.

BONAMINO, A.; SOUSA, S. Z. Três gerações de avaliação da educação básica no Brasil: interfaces com o currículo da/na escola. Educação e Pesquisa, São Paulo, v. 38, n. 2, p. 373-88, abr.jun.2012. DOI: 10.1590/S1517-97022012005000006

BRASIL. Levantamento do custo-aluno-ano em escolas de Educação Básica que oferecem condições de oferta para um ensino de qualidade - 2 etapa. Salvador, 2005, 118 p. Relatório Nacional da Pesquisa. Disponível em: $<$ http://www.isp.ufba.br/INEP\%2024-05.pdf>. Acesso em: 14 out. 2013.

. Ministério da Educação. BANCO INTERAMERICANO DE DESENVOLVIMENTO - BID. Melhores práticas em escolas de ensino médio no Brasil. Brasília, DF: INEP, 2010.

. Ministério da Educação; FUNDO DAS NAÇÕES UNIDAS PARA A INFÂNCIA - UNICEF. Aprova Brasil: O direito de aprender. Estudos de boas práticas de educação pública em escolas avaliadas pelo Prova Brasil: caderno de campo - orientações e instrumentos de trabalho para os pesquisadores. Brasília, DF, 2006. 
BRASIL. Ministério da Educação. Instituto Nacional de Estudos e Pesquisas Educacionais Anísio Teixeira - INEP. Censo escolar da educação básica 2012. 2013. Disponível em: <http://download.inep.gov.br/educacao_basica/ educacenso/documentos/2013/folder_censo_escolar_educacao_basica_2013. pdf $>$. Acesso em: 11 set. 2013.

. Redes de aprendizagem: boas práticas de municípios que garantem o direito de aprender. Brasília, DF, 2008.

BROOKE, N. Responsabilização educacional no Brasil. Revista Iberoamericana de Evaluación Educativa, v. 1, n. 1, p. 93-109, 2008.

BROOKE, N.; SOARES, J. F. Pesquisa em eficácia escolar: origens e trajetórias. Belo Horizonte: Ed. UFMG, 2008.

BUCHMANN, C. Measuring family background in international studies of education: conceptual issues and methodological challenges. In: PORTER, A.; GAMORAN, A. (Eds.). Methodological advances in cross-national surveys of educational achievement. Washington, DC: National Academy Press, 2002. p. 150-97.

COLEMAN, J. S. et al. Equality of educational opportunity. Washington, DC, 1966.

COOPER, W. W.; SEIFORD, L. M.; TONE, K. Data envelopment analysis: a comprehensive text with models, applications, references and DEA-solver software. New York: Springer Science, 2007.

DIAZ, M. D. M. Qualidade do gasto público municipal em ensino fundamental no Brasil. Revista de Economia Política, v. 32, n 1, p. 128-41, jan.-mar. 2012. DOI: 10.1590/S0101-31572012000100008

DWYER, T et al. Desvendando mitos: os computadores e o desempenho no sistema escolar. Educação \& Sociedade, v. 28, n. 101, p. 1303-28, set./dez. 2007. DOI: $10.1590 / \mathrm{S} 0101-73302007000400003$

ECONOMIST INTELLIGENCE UNIT. The learning curve: lessons in country performance in education. Londres: Pearson, 2012. (2012 Report). Disponível em: $<$ http://thelearningcurve.pearson.com/index/index-ranking $>$. Acesso em: 15 nov. 2013. 
ÉRNICA, M.; BATISTA, A. A. G. Educação em territórios de alta vulnerabilidade social na metrópole: um caso na periferia de São Paulo. São Paulo: Cenpec, 2011. (Informe de Pesquisa, 3).

EYNG, A. M. et al. Diversidade e padronização nas políticas educacionais: configurações da convivência escolar. Ensaio: Avaliação e Políticas Públicas em Educação, v. 21, n. 81, p. 773-800, out./dez. 2013. DOI: $10.1590 / \mathrm{S} 0104-40362013000400007$

FERNANDES, R.; GREMAUD, A. Qualidade da educação básica: avaliação, indicadores e metas. In: VELOSO, F. et al. (Orgs.). Educação básica no Brasil: construindo o país do futuro. Rio de Janeiro: Elsevier, 2009.

FRANCO, A. M. P. Os determinantes da qualidade da educação no Brasil. 2008. 146 f. Tese (Doutorado em Economia) - Universidade de São Paulo, São Paulo, 2008.

FRANCO, C. et al. Qualidade e eqüidade em educação: reconsiderando o significado de "fatores intraescolares". Ensaio: Avaliação e Políticas Públicas em Educação, v. 15 , n. 55, p. 277-98, abr.jun. 2007. DOI: 10.1590/S0104-40362007000200007

FRANCO, C. et al. Eficacia escolar en Brasil: investigando prácticas y políticas escolares moderadoras de desigualdades educacionales. In: CUETO, S. (Ed.). Educación y brechas de equidad en América Latina. Santiago: Preal, 2006. p. 223-49.

FREITAS, L. C. Eliminação adiada: o ocaso das classes populares no interior da escola e a ocultação da (má) qualidade do ensino. Educação \& Sociedade, v. 28 , n. 100 , p. $965-87$, out. 2007 . DOI: $10.1590 / \mathrm{S} 0101-73302007000300016$

GATTI, B. A. Avaliação de sistemas educacionais no Brasil. Revista de Ciências da Educação, n. 9, p. 7-17, maio/ago. 2009.

GOMES, C. A. A escola de qualidade para todos: abrindo as camadas da cebola. Ensaio: Avaliação e Políticas Públicas em Educação, v. 13, n. 48, p. 281-306, jul./set. 2005. DOI: 10.1590/S0104-40362005000300002

GOUVEIA, A. B.; SOUZA, A. R.; TAVARES, T. M. O IDEB e as políticas educacionais na região metropolitana de Curitiba. Estudos em Avaliação Educacional, v. 20, n. 42, p. 45-58, jan./abr. 2009. 
GREMAUD, A. P.; FELICIO, F.; BIONDI, R. L. Indicador de efeito escola: uma metodologia para a identificação dos sucessos escolares a partir dos dados da Prova Brasil. Brasília, DF: INEP, 2007.

GRUPO DE AVALIAÇÃO E MEDIDAS EDUCACIONAIS - GAME. Escola eficaz: um estudo de caso em três escolas da rede pública de ensino do Estado de Minas Gerais. Belo Horizonte, 2002.

LAREAU, A. Home advantage: social class and parental intervention in elementary education. Londres: The Falmer, 1989.

LEE, V. E., BRYK, A. S., SMITH, J. The organization of effective secondary schools. In: DARLING-HAMMOND, L. Review of research in education. Washigton, DC: American Education Research Association, 1993. p. 171-267.

MAY, H. A multilevel bayesian item response theory method for scaling socioeconomic status in international studies of education. Journal of Educational and Behavioral Statistics, v. 31, n. 1, p. 63-79, 2006.

MENDES JUNIOR, A. S. S. Vinculação de receitas orçamentárias e seu impacto nos índices da Educação Básica. Artigo (Especialista - Orçamento Público) - Instituto Serzedello Corrêa, Brasília, DF, 2010.

MESQUITA, S. Os resultados do Ideb no cotidiano escolar. Ensaio: Avaliação e Políticas Públicas em Educação, v. 20, n. 76, p. 587-606, jul./set. 2012. DOI: 10.1590/S0104-40362012000300009

OLIVEIRA, R. P.; ARAUJO, G. C. Qualidade do ensino: uma nova dimensão da luta pelo direito à educação. Revista Brasileira de Educação, n. 28, p. 5-23, jan./abr. 2005. DOI: 10.1590/S1413-24782005000100002

PADILHA, F. et al. As regularidades e exceções no desempenho no Ideb dos municípios. Estudos em Avaliação Educacional, v. 23, n. 51, p. 58-81, 2012.

PINTO, J. M. R. Novas fontes de financiamento e o custo aluno-qualidade (CAQ). In: ABMP, Todos Pela Educação (Org.). Justiça pela qualidade na educação. São Paulo: Saraiva, 2013. p. 288-311.

POSTLETHWAITE, T. N.; ROSS, K. N. Effective schools in reading: implications for educational planners: an exploratory study. The Hague: IEA, 1992. 
SALGADO JUNIOR, A. P.; NOVI, J. C. Proposta metodológica: avaliação externa e desempenho dos alunos. Revista Brasileira de Política e Administração da Educação, v. 30, n. 3, 2014. In press.

SAMMONS, P. As características-chave das escolas eficazes. In: BROOKE, N.; SOARES, J. F. (Orgs.). Pesquisa em eficácia escolar: origens e trajetórias. Belo Horizonte: UFMG, 2008. p. 335-92.

SAMMONS, P.; HILLMAN, J.; MORTIMORE, P. Key characteristics of effective schools: a review of school effectiveness research. London: Office for Standards in Education, 1995.

SARAIVA, L. A.; WAGNER, A. A relação família-escola sob a ótica de professores e pais de crianças que frequentam o ensino fundamental. Ensaio: Avaliação e Políticas Públicas em Educação, v. 21, n. 81, p. 739-72, out./dez. 2013. DOI: $10.1590 / \mathrm{S} 0104-40362013000400006$

SOARES, J. F. et al. Escola eficaz: um estudo de caso em três escolas. Belo Horizonte: Fundação Ford, 2002.

SOARES, J. F; CANDIAN, J. F. O efeito da escola básica brasileira: as evidências do PISA e do SAEB. Revista Contemporânea de Educação, v. 2, n. 4, p. 1-12, 2007.

SOARES, T. M. et al. A gestão escolar e o IDEB da escola. Pesquisa e Debate em Educação, v. 1, n. 1, p. 45-68, 2011.

SOUSA, S. Z.; OLIVEIRA, R. P. Sistemas estaduais de avaliação: uso dos resultados, implicações e tendências. Cadernos de Pesquisa, v. 40, n. 141, p. 793-822, dez. 2010. DOI: 10.1590/S0100-15742010000300007

TEIXEIRA, R. A. Espaços, recursos escolares e habilidades de leitura de estudantes da rede pública municipal do Rio de Janeiro: estudo exploratório. Revista Brasileira de Educação, v. 14, n. 41, p. 232-390, maio/ago. 2009. DOI: $10.1590 / \mathrm{S} 1413-24782009000200003$

YIN, R. K. Estudo de caso: planejamento e métodos. 3. ed. Porto Alegre: Bookman, 2005.

ZOGHBI, A. C. P. et al. Mensurando o desempenho e a eficiência dos gastos estaduais em educação fundamental e média. Estudos Econômicos, v. 39, n. 4, p. 785-809, out./dez. 2009. DOI: 10.1590/S0101-41612009000400004 


\section{Informações dos autores}

Alexandre Pereira Salgado Junior: Professor Associado do Departamento de Administração. Faculdade de Economia, Administração e Contabilidade, Universidade de São Paulo, Campus de Ribeirão Preto (FEA-RP / USP). Contato: asalgado@usp.br

Juliana Chiaretti Novi: Doutoranda em Administração de Organizações. Faculdade de Economia, Administração e Contabilidade, Universidade de São Paulo, Campus de Ribeirão Preto (FEA-RP / USP).Contato: juliana.cnovi@gmail.com 